\title{
ADVENTITIOUS ROOTS DEVELOPMENT AND ROOT SYSTEM ARCHITECTURE OF CHRYSANTHEMUM CUTTINGS
}

\author{
$\underline{\text { Ana COJOCARIU }}^{1}$, Elena-Liliana CHELARIU $^{2 *}$, Cătălin TĂNASE ${ }^{3}$ \\ 1 "Alexandru Ioan Cuza” University of Iaşi - "Anastasie Fătu” Botanical Garden, Dumbrava Roşie \\ Street no. 7-9, 700487 Iaşi - Romania. E-mail: ana.cojocariu@uaic.ro \\ ${ }^{2}$ Faculty of Horticulture, University of Agricultural Sciences and Veterinary Medicine Iaşi, Mihail \\ Sadoveanu Alley no. 3, 700490 Iaşi - Romania. * Corresponding author. E-mail: julia@ uaiasi.ro \\ ${ }^{3}$ Department of Biology, Faculty of Biology, "Alexandru Ioan Cuza" University of Iaşi, 20A Carol I, \\ 700505 Iaşi - Romania.
}

\begin{abstract}
Chrysanthemum have significant ornamental value and thus have a great economic importance and are also subjected to losses due to the insufficient rooting of the cuttings - the main method of vegetative propagation practiced for this crop. Insufficient understanding of the mechanisms that control adventitious root formation prevents the use of reliable technologies to improve the percentage of root adventitious development in cuttings of ornamental plants in general. Also, knowing the architecture of the root system helps correct application of chrysanthemum culture technologies. Two different cultivars of Chrysanthemum was investigated in order to describe the radicular architecture of cuttings, with emphasis on the root type and the influence of substrate on the developed model into four different variants of rooting substrate.
\end{abstract}

Keywords: adventitious roots, Chrysanthemum, cuttings, nutrients, root system, rooting substrate.

\section{Introduction}

The rooting of stem cuttings is one of the best methods of vegetative propagation in Chrysanthemum, to get high multiplication rates and also desired plants phenotypes. Propagation of Chrysanthemum and of other many ornamental plant species relies on adventitious root formation, which can be defined as roots developed under specific conditions from organs such as leaves and stems. Significant economic losses are still emerging as a result of insufficient rooting, despite of the intensive control over the environmental factors in the modern ornamental plant propagation industry.

Knowing the architecture of the root system helps correct application of chrysanthemum culture technologies in terms of properly positioning the crop on the appropriate fertility plots, ensuring soil mobilization according to plant requirements, application of fertilizers, and mechanical maintenance of crops in order keep intact the root system. The architectural model considers the root system as a set of connected axes, meaning a mathematical tree with nodes and branches. To describe the architecture of the radicular system, there are several models presented in the literature, but for studying the chrysanthemum cuttings in the proposed experiment was considered the hydraulic network method. This approach was developed by FITTER (1987), the general idea being to characterize the architecture of the root system and, in particular, the topology, using the mathematical tools developed in the field of hydrology to describe the drainage networks. For this purpose, the root system is defined as a set of links (linear segments between a 
terminal meristem area and a branch point or between two branch points), describing the topological parameters such as magnitude, altitude, topological index, etc. [FITTER \& al. 1991]. Two main types of architecture can be distinguished: the "herringbone" model, where the branching occurs only on a main axis (high hierarchy) and the "dichotomic" model, where branching on each axis results in equivalent axes (low hierarchy). Among these models there are many other intermediate patterns found in plants in general, being useful in appreciating the functional potential of the root system. The model shows the efficiency of exploiting the resources present in the substrate, with the link between the herringbone model and poor nutrient soils.

Several parameters that can be used in interpretations related to the efficiency of soil nutrient use [PAGES \& al. 2000] are indicated in the literature, of which, for the proposed experiment, those related to the total length of the roots formed on the cuttings, on the rooting period, the measurements taking place at the phase of transplantation of the cuttings into individual pots.

For determination of the total length of the roots, various measurement methods, whether manual or automated based on digital images, are available [DOWDY \& al. 1995], among which more commonly used are direct measurement, intersected line method and visual estimation method [OLIVEIRA \& al. 2000]. Direct measurements of the length of the roots can be practiced only on roots of large diameter, tree roots. Direct measurements of root lengths of herbaceous plants are rare and only for primary roots [SIVAKUMAR \& SALAAM, 1994], since it is not possible to directly measure the length of the total root (including the root) of a plant or even a sample root.

Using the intersected line method, the root length of a sample can be estimated using intersection counting techniques of a given data line system [NEWMAN, 1966; TENNANT, 1975]. Newman's proposed method is based on the relationship between the length of the root and the number of intersections between the roots and a system of lines spread over a well-defined surface, and arranged randomly with the lines of known lengths on the given area. MARSH (1971) simplified the method of NEWMAN \& TENNANT (1975), tested and popularized this modified method. The intersecting line method has become the standard manual technique for estimating the root length. The Intersected Line Method provides an estimate of the root length of the sample and is not a direct measurement. Sources of error arise only from random rooting on the grid, root visibility, definition of an intersection, and appreciation from the operator. With increased attention, it is possible to obtain coefficients of variation of the root length estimate of $5 \%$ or less [TENNANT, 1975], this being the minimum probable error. The variation coefficients for the Newman method are usually between 10 and 15\% [BOHM, 1979; BLAND \& MESARCH, 1990]. To minimize the error associated with the technique, is need to ensure proper lighting, the use of a magnifying glass to improve the visibility of the roots, improve the color contrast between the roots and the background, provide adequate breaks to avoid fatigue.

The purpose of the present study is to describe the radicular architecture of Chrysanthemum cuttings, with emphasis on the root type and the influence of substrate on the developed model into four different variants of rooting substrate. 


\section{Material and methods}

Plant Materials and Growing Conditions. The investigations were conducted during the period 2016-2017 on experimental field of "Anastasie Fatu" Botanical Garden belonging to "Alexandru Ioan Cuza" University of Iasi, Romania, in the heated greenhouses, with two Chrysanthemum cultivars - Chrysanthemum indicum L. cv. Carmina, noted in our research as (I) and Chrysanthemum $\times$ grandiflorum Ramat. cv. Yellow Stardust (II) (The Plant List 2014, The Plant List 2014a) - Figure 1. The cuttings were set about February 10, collected from stock-plants maintained in a vegetative state, in cold greenhouses with a main temperature of $13.8^{\circ} \mathrm{C}$ and with moderate irrigation once for a week.

Experimental Model. The evaluation of the qualitative and quantitative characters of the cuttings in the two cultivars of chrysanthemums consisted in measurements and observations on the root system of the cuttings in order to estimate the root architecture of the chrysanthemum cuttings. The rooting substrates was represented by four variants $(\mathrm{V})$, with organic (peat) and inorganic components (perlite and sand) combined into volumetric progressive proportions: V1 - peat $100 \%$, V2 - peat+perlite $(\mathrm{v} / \mathrm{v}), \mathrm{V} 3$ - peat+perlite+sand (v/v/v) and V4 - perlite 100\%. The experiment was set as bi-factorial, type 2x4, with first factor represented by species (two graduations - Chrysanthemum indicum L. and Chrysanthemum $\times$ grandiflorum Ramat.) and the second one by rooting substrate variant (four graduations - V1, V2, V3, V4).

In addition to the aspects regarding the development of the chrysanthemum cuttings, a number of parameters related to the development of the root system were taken into consideration, and the total length of the roots developed per cutting was measured after Newman method.

For roots density determination (D), the root length was reported at a given substrate volume, i.e. $60 \mathrm{ml}\left(0.06 \mathrm{~m}^{3}\right)$, the results being expressed in $\mathrm{m} / \mathrm{m}^{3}$. Formula used in the calculation [ALI, 2010]: Root density (D) = total root length / substrate volume.
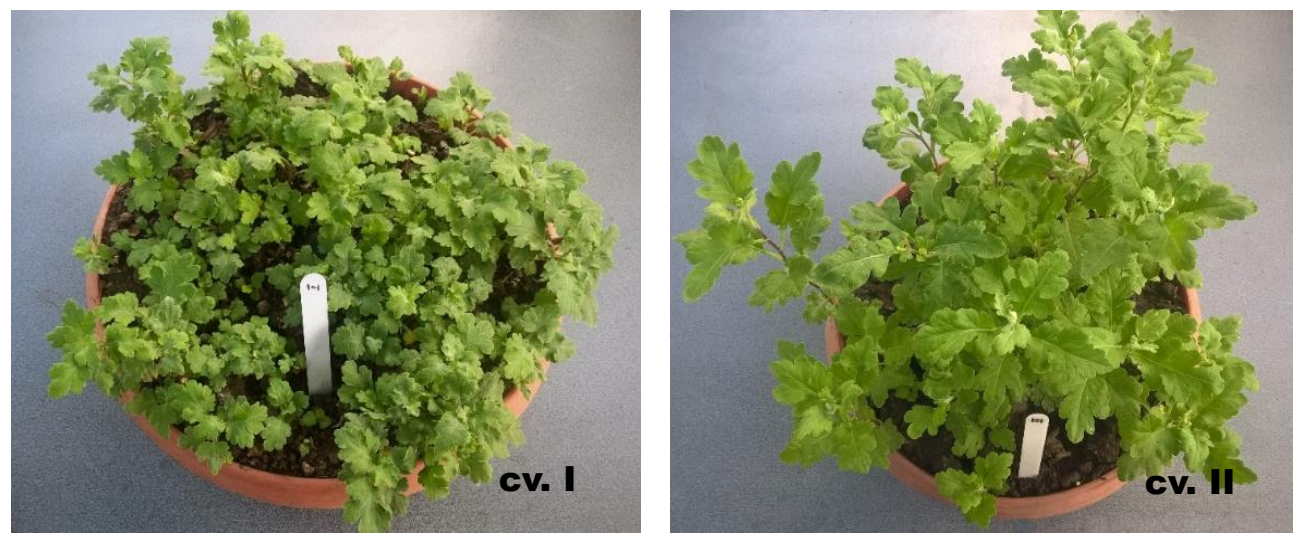

Figure 1. Stock-plants maintained in vegetative state: Chrysanthemum indicum L. cv. Carmina (I) and Chrysanthemum $\times$ grandiflorum Ramat. cv. Yellow Stardust (II) 


\section{Results and discussions}

Our results for Chysanthemum indicum (I) and Chrysanthemum $\times$ grandiflorum (II) cultivars indicate a correlation between the species and the rooting capacity. From the total loss of $5 \%$, it was $3.5 \%$ for cv. I (7 cuttings) and $1.5 \%$ for cv. II (3 cuttings). This difference, though insignificant, could be explained by the fact that Chrysanthemum $\times$ grandiflorum - a horticultural species cultivated for ornamental cut flowers, is a complex hybrid species less adapted to environmental variations, being cultivated only in protected areas, while Chrysanthemum indicum, is represented by rustic varieties with better tolerance to environmental variations, being cultivated successfully in open spaces.

Regarding the influence of rooting substrate type on total root length, one can notice differences both visually (Figure 2) and mathematics, based on data and calculation using the Newman formula.

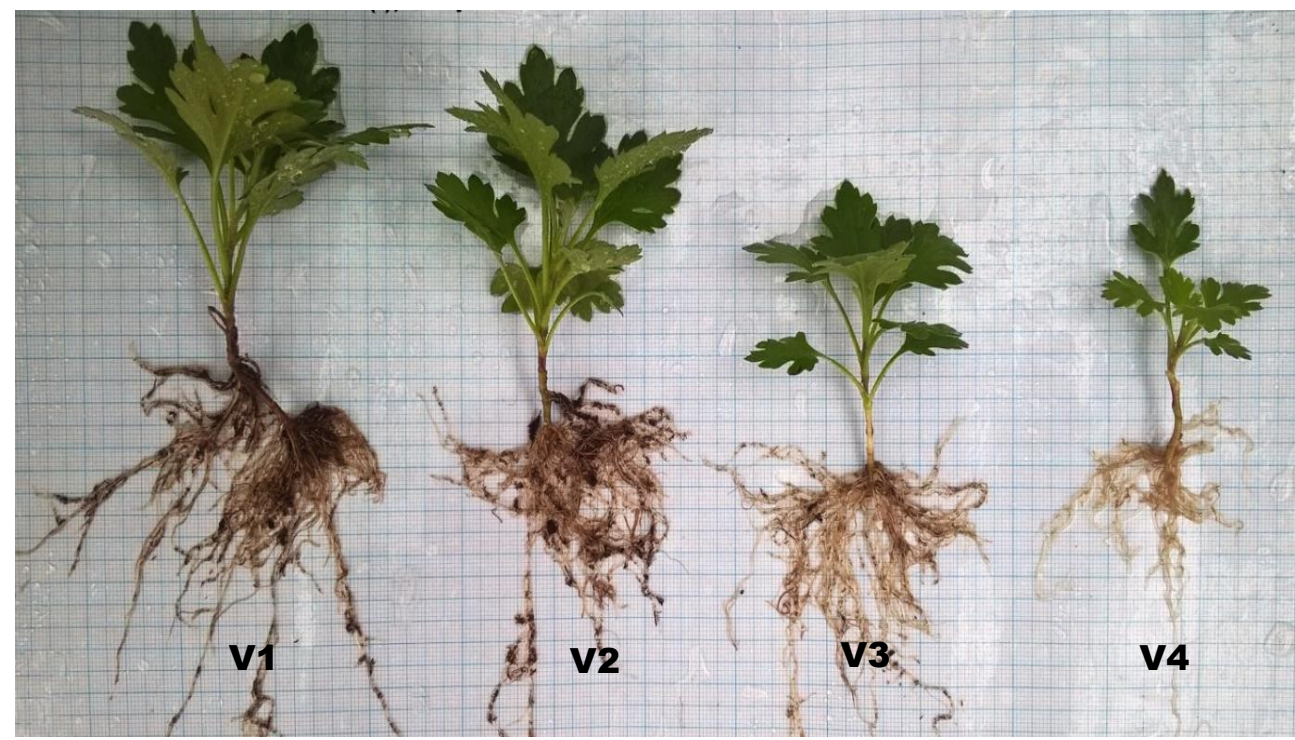

Figure 2. Influence of rooting substrate type on architecture and total root length of Chrysanthemum indicum cv. Carmina cuttings (V1-peat 100\%, V2-peat+perlite (v/v), V3-peat+perlite+sand (v/v/v) and V4-perlite 100\%; Scale - area of one minimal square is $1 \mathrm{~mm}^{2}$ )

Depending on the rooting substrate, for the Chrysanthemum cuttings it is noted that the most extensive root system was developed in the case of the V1 100\% peat variant $(62.55-65.88 \mathrm{~cm})$, followed by the combined variants V2 and V3 (average length between 49.81-61.86 cm). Cuttings that rooted into an inorganic substrate $(100 \%$ perlite $-\mathrm{V} 4)$ showed a less developed root system $(35.70-38.28 \mathrm{~cm})$ - Table 1, 2 and Figure 3.

Radicular plant system is in contact with a variety of abiotic factors, including soil water and nutrient availability, which influences both primary root growth and lateral root formation [INGRAM \& MALAMY, 2010]. These factors are constantly changing, and the ability of a plant to respond to these changes and to efficiently acquire the necessary water and nutrients has a direct impact on reproductive health and reproduction. 
COJOCARIU ANA \& al.

Table 1. Roots total length and roots density of Chrysanthemum cuttings $(\mathrm{cm})-$ Chrysanthemum indicum 'Carmina'

\begin{tabular}{|c|c|c|c|c|}
\hline \multirow{3}{*}{ cv. I } & \multicolumn{4}{|c|}{ Rooting substrate variants } \\
\hline & V1 & $\mathbf{V 2}$ & V3 & V4 \\
\hline & \multicolumn{4}{|c|}{ Roots total length per cutting, in cm (Newman formula) } \\
\hline $\mathbf{A}(\mathbf{c m})$ & $62.55 \pm \mathrm{SD}$ & $50.78 \pm \mathrm{SD}$ & $49.81 \pm \mathrm{SD}$ & $38.28 \pm \mathrm{SD}$ \\
\hline $\mathbf{D}\left(\mathbf{m} / \mathbf{m}^{3}\right)$ & 10.42 & 8.46 & 8.30 & 6.38 \\
\hline *SD & $* 4.13$ & $* 3.55$ & $* 3.29$ & $* 4.43$ \\
\hline
\end{tabular}

Table 2. Roots total length and roots density of Chrysanthemum cuttings $(\mathrm{cm})-$ Chrysanthemum $\times$ grandiflorum 'Yellow Stardust'

\begin{tabular}{|l|c|c|c|c|}
\hline \multirow{2}{*}{ cv. II } & \multicolumn{4}{|c|}{ Rooting substrate variants } \\
\cline { 2 - 5 } & $\mathbf{V 1}$ & V2 & V3 & V4 \\
\cline { 2 - 5 } & \multicolumn{4}{|c|}{ Roots total length per cutting, in cm (Newman formula) } \\
\hline $\mathbf{A}(\mathbf{c m})$ & $65.88 \pm$ SD & $61.86 \pm$ SD & $61.71 \pm$ SD & $35.70 \pm$ SD \\
\hline $\mathbf{D}\left(\mathbf{m} / \mathbf{m}^{\mathbf{3}}\right)$ & 10.98 & 10.31 & 10.28 & 5.95 \\
\hline *SD & $* 3.13$ & $* 3.55$ & $* 3.09$ & $* 2.32$ \\
\hline
\end{tabular}

Abbreviations: I - Chrysanthemum $\times$ grandiflorum Ramat. cv. Yellow Stardust, $\mathbf{A}-$ average root length, SD Standard Deviation, $\mathbf{D}$ - root density, $\mathbf{V}$ - variant of rooting substrate: V1 - peat (100\%), V2 - peat+perlite (v/v), V3 - peat+perlite+sand (v/v/v), V4 - perlite (100\%), $\mathbf{m}$ - meter, $\mathbf{c m}$ - centimeter.

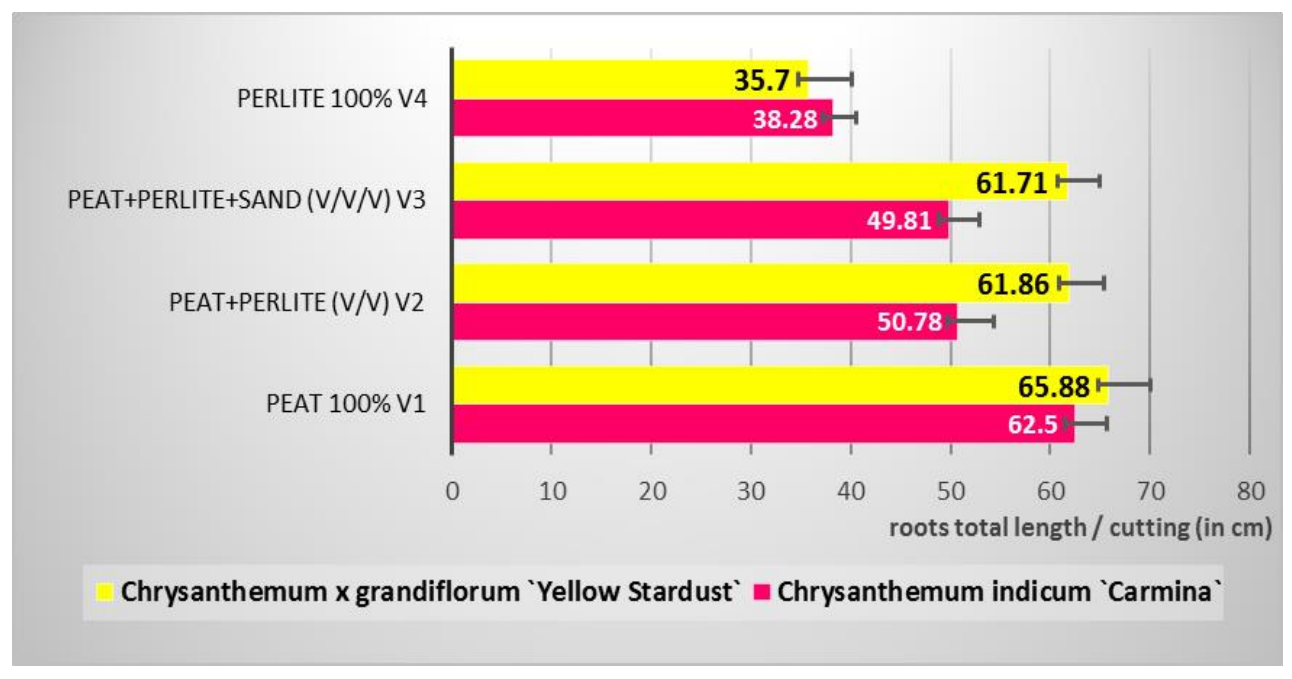

Figure 3. Roots total length of Chrysanthemum cuttings (average in $\mathrm{cm}$ ) (bars - Standard Deviation) 
Considering the fact that for rooting of cuttings, no substances have been used to stimulate the rhizogenesis, the total loss of the cuttings of the chrysanthemums was only $5 \%$. This insignificant percentage indicates that the genus Chrysanthemum s.1. has a very good rooting capacity for cuttings, even in the absence of hormonal stimulators, which are indicated to be used for vegetative propagation, especially in heavily rooted plant species. Data from the literature indicates a correlation between the cultivar and the successful rooting of the cuttings, but with the use of IBA in different concentrations, the best results being obtained for Chrysanthemum cv. Crimson Robe, cv. Polario, cv. Escort, cv. Sterling and cv. Luysona at $50 \mathrm{ppm}$ IBA, by spraying or immersing in the rooting stimulator, resulting in a much more compact radicular system [PETTER, 1992].

Knowing the architecture of the root system improve the correct application of chrysanthemum culture technologies in terms of properly positioning the crop on the appropriate fertility plots, ensuring soil loosening according to plant requirements, application of fertilizers, and mechanical maintenance of crops in order to does not destroy the root system. The investigation reveal the development of a "dichotomic" radicular system in the chrysanthemum cuttings - Figure 4, in which branching occurs on each axis, resulting in equivalent axes (low hierarchy). The radicular architecture model shows the efficiency of exploitation of the resources present in the substrate, the link between the developed radicular model and the substrate characteristics in terms of nutrient availability [FITTER \& al. 1991]. While the herringbone model is associated with plants growing in poor nutrient soils, the dichotomic pattern observed at chrysanthemum cuttings indicate a nutrient rich substrate.

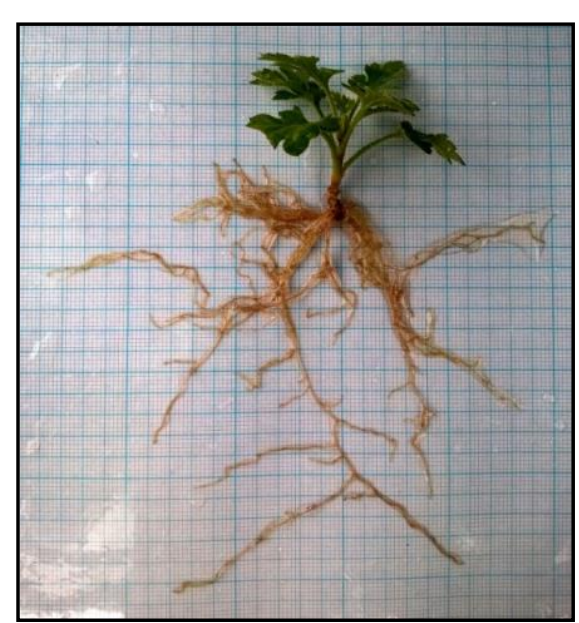

Figure 4. Dichotomic radicular architecture of Chrysanthemum cuttings (Scale - area of one minimal square is $1 \mathrm{~mm}^{2}$ )
There are a number of materials that can be used either separately or in various combinations to obtain rooting mixtures, choosing a particular material being determined by the availability, cost and local experience of its use. In northeastern Europe, peat is the most commonly used material as rooting substrate, and in the US the crumbly bark, vermiculite and perlite, which are also widely used materials. The most important factor in choosing a material for earth mixtures is that it must not contain toxic substances for plants. A large number of materials meet this requirement and can be successfully used, provided that the management of the substrate composition (i.e. the addition of nutrients or drainage material) is adapted to the requirements of the environment and culture [BUNT, 1988].

Our results support a relationship between the type of rooting substrate and the capacity to rooting, a lower rate being observed for peat and perlite+peat substrates $(96 \%)$, while for the peat+perlite+sand and perlite, the rate was $99 \%$. The explanation for this difference could be the fact that the peat is a substrate that becomes quite compact, which does not allow a good circulation of water and air at the root system level, while the perlite, through the porous structure allows the aeration and constant water drainage. KHER (1976) reported coarse sand for 
COJOCARIU ANA \& al.

chrysanthemums as the optimal rooting medium, also based on the high drainage and aeration capacity at the roots level. According to BARBAROSA \& al. (2000) expanded clay can be considered an excellent medium for chrysanthemum culture into hydroponic system, with good aeration and drainage, and also the absence of pathogens.

\section{Conclusions}

The present study highlight several aspects related to Chrysanthemum vegetative multiplication and the influence of some factors (such as horticultural variety, type of rooting substrate) on the yield of planting material. Depending on the studied cultivars, the best results were obtained for Chrysanthemum indicum, indicating a better adaptation and a higher rooting capacity for this species that do not require special conditions for cultivation in enclosed spaces, as in the case of Chrysanthemum $\times$ grandiflorum.

Based on the researches made with the four variants of the rooting substrate, there was a better rooting in the peat+perlite (v/v) and perlite variant (V2, V4), characterized by a better drainage capacity and aeration. By correlating the results of the development of the root system and the growth rate after rooting, we can conclude that $100 \%$ organic or inorganic (peat or perlite) rooting substrate is not recommended. More variants and volumetric progression combinations are more appropriate to ensure drainage of water and aeration in the newly formed roots. In $100 \%$ peat, the percentage of initial losses is higher, while perlite, although rooted cuttings in a higher percentage than peat, fail to maintain the growth rate of an organic environment such as peat.

Knowing the particular type of radicular architecture can improve the correct application of chrysanthemum culture technologies as properly positioning of the crops into the appropriate fertility plots, adequate application of fertilizers, and mechanical maintenance of chrysanthemum crops in order to protect the root system of the plants.

\section{Notes on contributors}

Ana COJOCARIU - is a plant biologist, $\mathrm{PhD}$ with a special interest in ornamental plants cultivation, and work as coordinator of activities into Chrysanthemum Collection Section of Botanical Garden Iasi-Romania. Areas of competence is also represented by ex situ conservation of economically important plants, fungal ecology - the study of stationary conditions that affect the diversity of lignicolous macromycetes species.

Elena Liliana CHELARIU - is an Associate professor PhD at University of Agricultural Sciences and Veterinary Medicine from Iaşi, Faculty of Horticulture, Discipline of Floriculture, with competences in: Floriculture and production of ornamental plants' seedling material; Breeding of ornamental plants; Preservation and capitalization of ornamental flora biodiversity. Research domains: Biology, ecology, cropping technology and improvement methods for capitalization of floral species; evaluation and completion of ornamental grasses assortment cultivated in Romania; capitalization for ornamental purposes of spontaneous flora biodiversity; preservation of germplasm fund at ornamental plants.

Cătălin TĂNASE - is a Professor PhD. at the Faculty of Biology of "Alexandru Ioan Cuza" University of Iasi-Romania, Director of the Botanical Garden of Iasi, with competences in Botany, Conservation of Plant and Fungi Diversity, management of protected areas, culture conditions optimization for growing fungi in situ and ex situ, isolation of fungi with application in bioremediation, phytopathology - structural, physiological and biochemical modifications, produced by pathogen fungi. 


\section{References}

ALI F. 2010. Use of vegetation for slope protection: Root mechanical properties of some tropical plants. Int. J. Phys. Sci. 5(5): 496-506.

BARBOSA J. G., KAMPF A. N., MARTineZ H. E. P., KOLlER O. C. \& HUMBERTO B. 2000. Chrysanthemum cultivation in expanded clay. I. Effect of the Nitrogen-Phosphorus-Potassium ratio in the nutrient solution. Journal of Plant Nutrition. 23(9): 1327-1336.

BLAND W. L. \& MESARCH M. A. 1990. Counting error in the line-intercept method of measuring root length. Plant and Soil. 125(1): 155-157. https://doi.org/10.1007/BF00010758.

BÖHM W. 1979. Methods of studying root systems, In: Ecological Studies: Analysis and Synthesis, Vol. 33: 188 pp. Springer, Berlin Heidelberg New York.

BUNT A. C. 1988. Media and mixes for container-grown plants: a manual on the preparation and use of growing media for pot plants. $2^{\text {nd }}$ ed., Academic Division of Unwin Hyman Ltd, UK, 309 pp.

DOWDY R. H., NATER E. A. \& DOLAN M. S. 1995. Quantification of the length and diameter of root segments with public domain software. Commun. Soil Sci Plant. Anal. 26(3\&4): 459-468. https://doi.org/10.1080/00103629509369311

FITTER A. H. 1987. An architectural approach to the comparative ecology of plant root systems. New Phytol. 106 (Suppl): 61-77. https://doi.org/10.1111/j.1469-8137.1987.tb04683.x

FITTER A. H., STICKLAND T. R., HARVEY M. L. \& WILSON G. W. 1991. Architectural analysis of plant root systems. 1. Architectural correlates of exploitation efficiency. New Phytol. 118: 375-382. https://doi.org/10.1111/j.1469-8137.1991.tb00018.x

INGRAM P. A. \& MALAMY J. E. 2010. Root System Architecture, pp. 75-117. In: KADER J. K. \& DELSENY M. (Eds.). 2010. Advances in Botanical Research, vol. 55. Elsevier Science Publishing.

KHER M. A. 1976. Different rooting media effecting the rooting of chrysanthemum. Indian J. Orn. Hort. 7: 3639.

MARSH B. a'B. 1971. Measurement of length in random arrangements of lines. J. Appl. Ecol. 8: 265-267. doi: $10.2307 / 2402144$

NEWMAN E. I. 1966. A method for estimating the total length of root in a sample. J. Appl. Ecol. 3: 139-145. doi: $10.2307 / 2401670$

OLIVEIRA M. R. G., VAN NOORDWIJK M., GAZE S. R., BROUWER G., BONA S., MOSCA G. \& HAIRIAH K. 2000. Auger sampling, ingrowth cores and pinboard methods. In: SMIT A. L. \& al. (eds.). 2000. Root methods. A Handbook: 175-210. Springer-Verlag Berlin Heidelberg. doi: 10.1007/978-3-66204188-8

PAGES L., ASSENG S., PELLERIN S. \& DIGGLE A. 2000. Modelling Root System Growth and Architecture. In: SMIT A. L. \& al. (eds.). (2000). Root methods. A Handbook: 113-146. Springer-Verlag Berlin Heidelberg. doi: 10.1007/978-3-662-04188-8

PETTER S. 1992. More marketable plants in a shorter time. Gartenbau Magazin. 1(6): 68-70.

SIVAKUMAR M. V. K. \& SALAAM S. A. 1994. A wet excavation method for root shoot studies of pearl millet on the sandy soils of the Sahel. Exp. Agric. 30: 329-336. https://doi.org/10.1017/S0014479700024431

TENNANT D. 1975. A test of a modified line intersect method of estimating root length. J. Ecol. 63(3): 995-1001. doi: $10.2307 / 2258617$

THE PLANT LIST. 2014. Chrysanthemum $\times$ grandiflorum Ramat. In: The plant list. A working list of all plant species. http://www.theplantlist.org/tpl1.1/record/gcc-144228. Accessed: 21 June 2018.

THE PLANT LIST. 2014a. Chrysanthemum indicum L. In: The plant list. A working list of all plant species. http://www.theplantlist.org/tpl1.1/record/gcc-139655. Accessed: 21 June 2018.

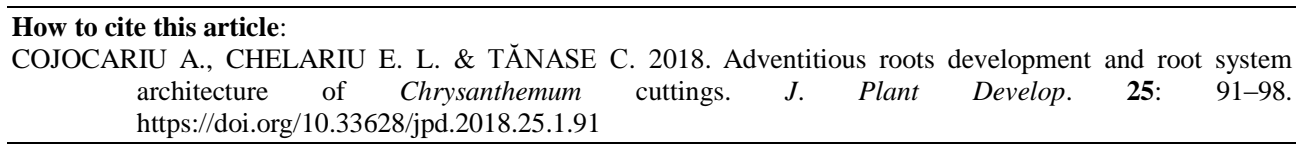

